\title{
Testing the hypothesis that variations in atmospheric water vapour are the main cause of fluctuations in global temperature
}

\author{
Ivan R. Kennedy ${ }^{1}$ and Migdat Hodzic ${ }^{2}$ \\ ${ }^{1}$ University of Sydney, NSW, Australia \\ ${ }^{2}$ American University in Bosnia and Herzegovina, Sarajevo, B\&H
}

Article Info

Article history:

Received Apr 10, 2019

\section{Keyword:}

OLR Global Forcing

Water Vapour

Greenhouse Effect

Heat Transfer

Anthropogenic Climate

Change

\begin{abstract}
A hypothesis that the increasing application of both surface and ground water for irrigation of crops is a significant source of anthropogenic global warming is tested. In climate models, water is already assigned a major secondary amplifying role in warming, solely as a positive feedback from an atmosphere previously warmed by other GHGs. However, this conclusion ignores the direct anthropogenic forcing from increasing use of water in dry regions to grow crops for the human population. The area irrigated worldwide increased by around $1.5 \%$ annually between 1960 and 2000, almost trebling in magnitude. Importantly, though only a small proportion of the Earth's surface, this additional water vapour is dynamically focussed on dry land, intensifying its potential to elevate the troposphere and reduce the regional OLR. Our modelling analysis suggests that the increase in atmospheric water vapour from irrigation could be significantly more than $1 \%$ by 2050 compared to 1950 , imposing a global forcing exceeding $1.0 \mathrm{~W} / \mathrm{m}^{2}$. Fortunately, this hypothesis can be tested, for example, using the satellite data on OLR acquired since the 1970s, relating this to local trends of increasing irrigation or major floods in arid regions. If found consistent with the data, current proposals to mitigate climate change by limiting combustion of fossil fuels may prove less effective. This prediction regarding the warming effect of increasing irrigation is tested using NCAR reanalysis data made possible by the natural experiments of the periodic flooding of Lake Eyre in Australia's semi-arid interior. It is recommended that this hypothesis be tested using data from local studies in irrigated regions such as changes in outgoing longwave radiation and in increased absorption of incoming shortwave radiation in air.
\end{abstract}

\section{Corresponding Author:}

\section{Migdat HODZIC}

AUBIH, Sarajevo, Bosnia and Herzegovina

Email: migdathodzic@gmail.com

\section{Introduction}

Global warming issues have caused intensive research work in related areas, from land use, to urban environment to data science use in order to understand its effects better [25], [26], [27]. In this paper we focus on water related effects on global warming. Although water is recognised as the main cause of the greenhouse effect warming the Earth $33{ }^{\circ} \mathrm{C}$ above its black body temperature, water vapour is usually given a secondary role in global models, as a positive feedback from warming by all other causes. Despite its dominant effect in generating the weather, changes related to water are not seen as having a primary role in climate change, the 
focus being primarily on $\mathrm{CO}_{2}$. With positive feedback from primary warming, the effect of increasing $\mathrm{CO}_{2}$ is trebled [15] by water vapour increase. This conclusion is based on the perception that there are no significant trends in the hydrological cycle that could cause climate forcing. But this overlooks the effect of more than $3500 \mathrm{~km}^{3}$ of extra surface and ground water used annually in irrigation [17] to grow food for the human population. This quantity of extra water increases steadily year by year, well correlated with increasing atmospheric $\mathrm{CO}_{2}$, growing about $60 \%$ of world food requirements. Even so, the amount used in irrigation probably only adds about $3 \%$ to the annual hydrological cycle [9] of $113,000 \mathrm{~km}^{3}$. Is this sufficient to exert a significant extra greenhouse effect? Here we advance the hypothesis that it does and should be included in climate models. A critical assumption of the IPCC consensus of global warming is that an increasing concentration of $\mathrm{CO}_{2}$ causes more retention of radiant heat near the top of the atmosphere, largely as a result of reduced emission of its spectral wavelengths centred on 15 microns. The radiative-convective model assumes that the lowered emissions at reduced pressure, number density and higher, colder altitudes from this GHG now provides an independent and sustained forcing exceeding 1-2 $\mathrm{W}$ per $\mathrm{m}^{2}$. It is assumed that once this reduction in OLR in the air column from increasing $\mathrm{CO}_{2}$ has occurred it must be compensated by increased OLR at different wavelengths elsewhere, maintaining balance with incoming radiation. This critical assumption still lacks empirical confirmation.

\section{Hypothesis}

\subsection{Resistance of Heat Flow to Space by Greenhouse Gases}

The importance of water in helping to keep the Earth's atmosphere warm in the short term is beyond dispute. Table 1 summarises previously estimated rates for thermal energy flows into and out of the atmosphere [23]. As shown in the table, more than $80 \%$ of the power by which the temperature of air is maintained above the Earth's black body temperature of $-18 \mathrm{C}$ is facilitated by water. Most significant of these air warming inputs from water is the greenhouse effect by which water vapour absorbs longwave radiation emitted from the surface, retaining more energy in air. However, warming from absorption of specific quanta by water vapour of incoming short wave solar radiation (ISR) and the latent heat of condensation of water vapour, exceeding the cooling effect of vertical convection, also contribute to warming of air.

Table 1: Mean global transfer of thermal energy into the atmosphere $\left(\mathrm{W} / \mathrm{m}^{2}\right)$ derived from [24] and [23]

\begin{tabular}{|l|c|c|c|c|c|c|}
\hline Agent & $\begin{array}{c}\text { Incoming } \\
\text { shortwave }\end{array}$ & $\begin{array}{c}\text { Latent heat } \\
\text { condensation }\end{array}$ & $\begin{array}{c}\text { Greenhouse } \\
\text { absorption }\end{array}$ & Thermals & $\begin{array}{c}\text { Heat transfer } \\
\text { to air }\end{array}$ & Ex TOA \\
\hline Water & 65 & 80 & 117 & - & 272 & 154 \\
\hline $\mathrm{CO}_{2}$ & 0 & 0 & 30 & - & 30 & 28 \\
\hline $\begin{array}{l}\text { Other } \\
\text { GHGs }\end{array}$ & 13 & 0 & 7 & - & 14 & 7 \\
\hline Surface & 161 & - & & 17 & 17 & 51 \\
\hline Total & 239 & 80 & 157 & 17 & 333 & 239 \\
\hline
\end{tabular}

Thus, the greenhouse gas (GHG) content of the atmosphere effectively provides resistance to heat flow to space increasing the transient storage of solar energy, with a warming effect analogous to resistances in an electrical circuit. By comparison to water, other polyatomic greenhouse gases like $\mathrm{CO}_{2}$ play a minor role in this process, totalling less than $20 \%$ of warming. Furthermore, the fact that the minor GHGs are relatively well-mixed by the turbulence in the troposphere, unlike water, means that we cannot expect to observe spatial variations in their effects. Furthermore, the heat capacity of non-greenhouse gases provides some $99 \%$ of the thermal inertia of the troposphere, although only greenhouse gases capable of longwave radiation by vibrational and rotational quanta can contribute to cooling by radiation through the top of the atmosphere as OLR. Figure 1 contrasts schematically the typical variation of outgoing longwave radiation (OLR) over marine and terrestrial environments. On well-watered land such as southern China much less direct emission of OLR to space occurs, in contrast to Quetta, Pakistan, on the same latitude with similar incoming shortwave radiation (ISR). In contrast to humid atmospheres on land and tropical seas, relatively arid regions such as the Sahara, the Middle East and Australia provide heat vents effectively cooling the Earth, solely as a result of the radiant emissions from GHGs as OLR. The varying global emissions of OLR estimated for typical marine and terrestrial regions shown in Figure 2 mirror this scheme. Clearly, water vapour is the most critical factor 
in the mechanism by which the air column of the lower troposphere is charged with heat energy. It is of interest from this figure and in Table 1 that the exact sum of the effects of all greenhouse gases in directly warming air, including conduction from the surface, charges the lower atmosphere with sufficient heat to generate the downwelling radiation from greenhouse gases directed towards the surface [12]. Water is the main source of this back radiation [18], well understood to be responsible for keeping the surface air warmer in humid atmospheres, thus raising the minimum temperature. None of the variation in OLR in Figure 1 can be attributed to the well-mixed GHGs such as $\mathrm{CO}_{2}$. Furthermore, unlike the greenhouse effect of $\mathrm{CO}_{2}$, which is regarded as increasing only in in a logarithmic manner as its concentration rises, the greenhouse effect of water on retaining heat in the atmosphere should vary more linearly, even in the case of absorption of surface radiation, as its vapour spreads into dryer atmospheres; this potential is illustrated in Fig. 1 in the descending zones of Hadley cells at sub-tropical latitudes.

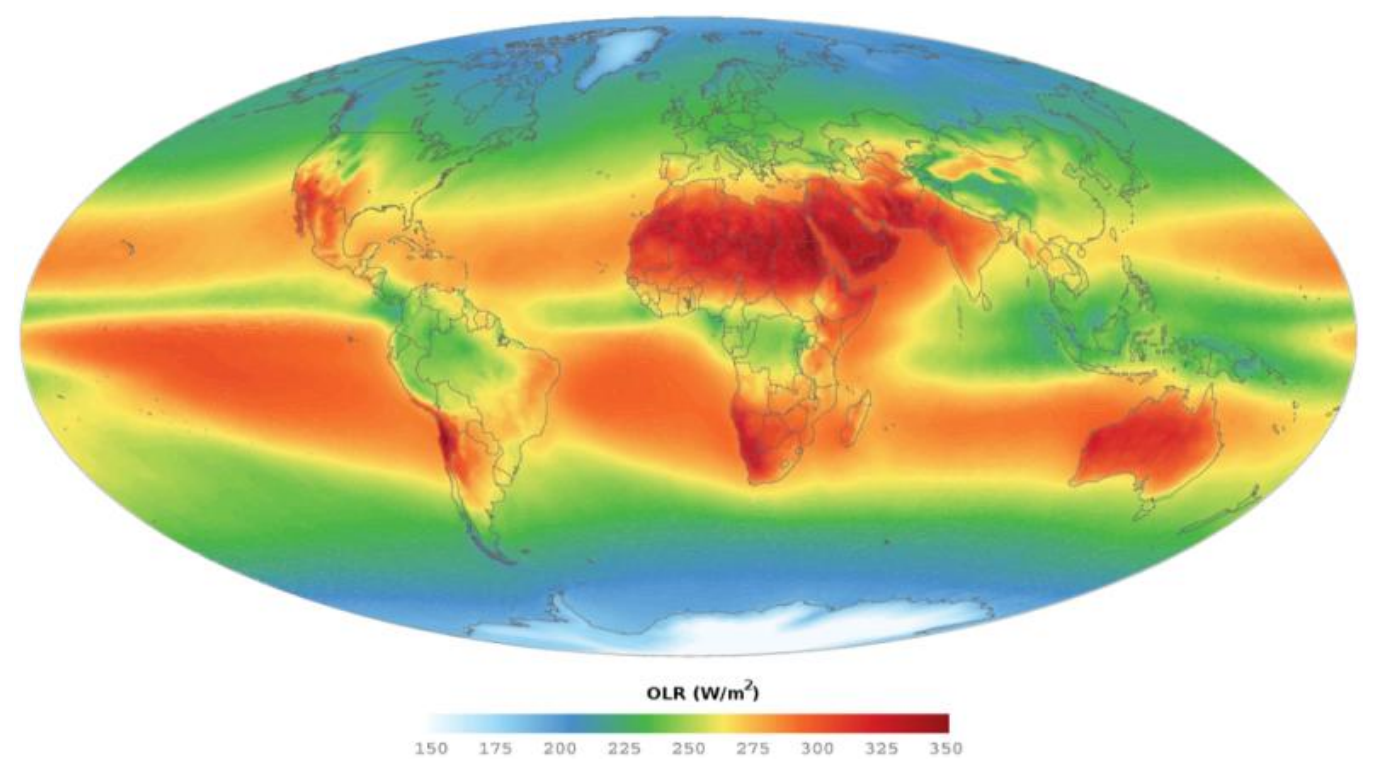

Fig. 1 Global values of mean OLR from 2003-2011 (downloaded August 2, 2017, AIRS OLR 2003-2011 average htpp://mirador.gsfc.nasa.gov/ estimated by Giorgio, G.P., June 24, 2014). The russet areas show regions of greater OLR, with outgoing radiation above the average of ca. $240 \mathrm{~W}$ per $\mathrm{m}^{2}$, thus tending to cool the Earth. Note how the upper troposphere above arid continental regions provides a vent for the greatest rate of cooling

\subsection{Establishing a model}

We employ a novel dynamic model for testing atmospheric processes and the role of water still being developed; this model incorporates the power of the transfers of thermal energy $\left(\mathrm{W} / \mathrm{m}^{2}\right)$, coupled to thermodynamics of atmospheric profiles with the temperature gradient established by the virial action theorem [11]. To emphasise local variation in water, these energy transfer processes are shown in Figure 2 for two different scenarios, similar to those given by [22] [23] [24] [25] for global averages. Local variation in outgoing longwave radiation (OLR) from the global average of $239 \mathrm{~W} / \mathrm{m}^{2}$, is largely a function of variation in water vapour content (relative and humidity), that involves contributions from absorption of incoming solar radiation in the atmosphere (A), transfer of latent heat of evapotranspiration from the surface to the lower troposphere (E) as well as the classical greenhouse effect $(\mathrm{G})$ as the difference between radiation from the surface $\left(F=k T^{4}\right)$, where $k$ is the Stefan-Boltzmann constant $\left(5.670367 \times 10^{-8}\right)$. It should be noted that, although $\mathrm{CO}_{2}$ makes a significant contribution (ca. 20\%) to the greenhouse effect $(\mathrm{G})$ by its control of specific radiation at the top of the troposphere as a result of its elevation of the effective emission of its characteristic wavelength of radiation to space, thus lowering the rate of cooling, it has only a minor effect in the continuous transfer of heat into air. Water is responsible for more than $80 \%$ of tropospheric warming $(\mathrm{H})$ and more than $60 \%$ of the greenhouse effect $(\mathrm{G})$. Of the $33 \mathrm{C}$ of total warming of Earth from its black body temperature of $255 \mathrm{~K}$ to $288 \mathrm{~K}$, water contributes some $25 \mathrm{C}$, including its role in absorption of shortwave radiation (ISR). 
Table 2 employs model data as shown in Figure 2 to estimate rates of warming of the tropospheric profile under typical marine, terrestrial and global mean values as computed in [22]. This model emphasises the important role that water vapour, given that $\mathrm{CO}_{2}$ concentration is the same everywhere in a well-mixed atmosphere. Yet the transfer of heat into a typical dry terrestrial atmosphere is just over $60 \%$ of that in a marine atmosphere. Given that atmospheres on land in moisture deficit have a significant potential for additional forcing for global warming, the current modelling suggesting that the role of water is solely as a positive feedback to prior warming by other factors, there may be a need to reconsider this assumption. The heating rate will be offset by various mechanisms for cooling of the air column, most obviously as the OLR, but also by the development of advection processes (both kinetic and cooling potential energies) carrying heat towards the poles. These can be augmented by accelerated heat transfers from the surface of the ocean such as in cyclones, but these processes will not be dealt with in this paper.

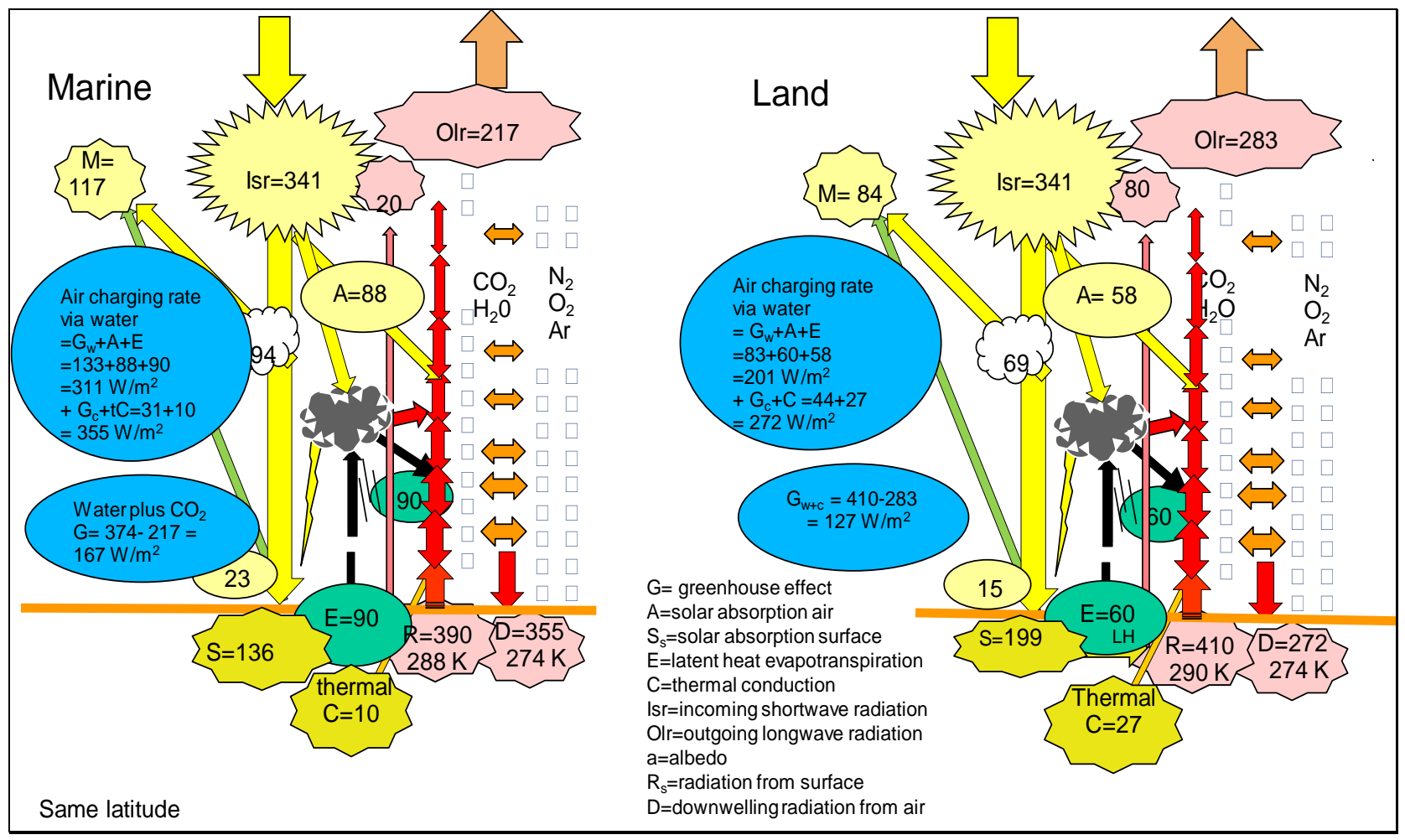

Fig. 2 Mid-latitude marine and terrestrial regions showing possible variations in heat transfer to air attributable to GHGs including water. Charging rates of air $(\mathrm{H})$ are estimated from the equation $\mathrm{H}=\mathrm{G}+\mathrm{A}+$ $\mathrm{E}+\mathrm{C}$, where the greenhouse effect $\mathrm{G}$ is given by $\mathrm{R}-\mathrm{O}$, as defined in the figure. Local temperature variations are a function of $\mathrm{H}$, the heat capacity of air and the processes for transfer of heat away from a locality (convection and advection, outgoing radiation as OLR). The inclusion of $\mathrm{D}$, downwelling radiation as equal to $\mathrm{H}$, may be misleading locally, as these need only be equal in a global sense.

Table 2: Calculation of heating rate for air columns

\begin{tabular}{|l|c|c|c|c|c|c|c|}
\hline Scenario & $\begin{array}{c}\text { Solar } \\
\text { absorption } \\
\mathrm{A}\end{array}$ & Evaporation & Thermals & $\begin{array}{c}\text { Surface } \\
\text { Radiation } \\
\mathrm{R}\end{array}$ & $\begin{array}{c}\text { OLR } \\
\mathrm{O}\end{array}$ & $\begin{array}{c}\text { Green- } \\
\text { house } \\
\mathrm{G}\end{array}$ & $\begin{array}{c}\text { Heating rate } \\
\text { K/sec } \\
\mathrm{dT} / \mathrm{dt}\end{array}$ \\
\hline Marine & 88 & 90 & 10 & 390 & 217 & 173 & $3.3744 \times 10^{-2}$ \\
\hline Terrestrial & 58 & 60 & 27 & 401 & 283 & 127 & $2.2686 \times 10^{-2}$ \\
\hline Global & 78 & 80 & 17 & 390 & 239 & 157 & $2.9707 \times 10^{-2}$ \\
\hline
\end{tabular}

Note: Calculated using model equation $\mathrm{H}=\mathrm{A}+\mathrm{E}+\mathrm{C}+\mathrm{G} \mathrm{W} / \mathrm{m}^{2}$, where $\mathrm{G}=\mathrm{R}-\mathrm{O} ; \mathrm{R}$ is estimated from the Stefan-

Boltzmann equation $\mathrm{R}=\sigma \mathrm{T}^{4}$ whereas heating rate involves division by the mass of air in each column $\left(1.0339 \times 10^{4} \mathrm{~kg}\right.$ air $\left./ \mathrm{m}^{2}\right)$ and then by the heat capacity $(1.0063 \mathrm{~kJ} / \mathrm{kg})$. 
An approximately linear response in increasing air temperature to changes in atmospheric water content is reasonable. Unlike the well-mixed $\mathrm{CO}_{2}$, there are marked spatial and temporal variations in atmospheric water content, with much of the Earth's surface in significant deficit, particularly in the sub-tropical zone subject to Hadley cell recycling, emphasised over semi-arid land. To the extent that additional water vapour spills over into these dryer regions on land the greater the area of the Earth that is subject to the greenhouse effect. This response can be contrasted to the effect of increasing $\mathrm{CO}_{2}$, which has a logarithmic relationship between climate forcing and concentration in the atmosphere [14], [15], each doubling causing a similar increase in temperature. Because there is no obvious regional effect of $\mathrm{CO}_{2}$ on the weather or regional climate, the effect of any increases in its concentration can only be theoretically inferred. If additional heat is retained in the atmosphere by increasing greenhouse effects from $\mathrm{CO}_{2}$ or water, the air temperature near the surface is expected to increase to keep global values of ISR and OLR in balance. A critical assumption of the IPCC consensus for climate change is that increasing $\mathrm{CO}_{2}$ causes more retention of heat in air near the top of the troposphere, largely as reduced emission from the edges of its spectral peak centred on 15 microns. This edge effect is predicted to be visible from space as a cooling of its spectrum, providing a negative forcing of 1-2 W per $\mathrm{m}^{2}$. It is assumed that this forcing must be compensated by increased OLR at different wavelengths as a result of the increased temperature.

\section{Antithesis}

\subsection{Stefan-Boltzmann Analysis of The Effect of Irrigation on Global Climate}

In Table 3 using the Stefan-Boltzmann equation, data supporting the primary forcing role of water vapour in global warming is summarised. From spectral analysis, some $60-70 \%$ of the greenhouse effect is attributed to water [20] [22] , a result of its ability to absorb surface longwave radiation across most of the Earth's emission spectrum, particularly at lower altitudes where water is concentrated. By comparison, absorption by other greenhouse gases including $\mathrm{CO}_{2}$ is more restricted in wavelength and of lower magnitude except at higher altitudes. According to global estimates given by [21], the greenhouse effect has an average magnitude worldwide of 157 Watts per square metre $\left(\mathrm{W} / \mathrm{m}^{2}\right)$, the difference between the mean surface emission $(396$ $\mathrm{W} / \mathrm{m}^{2}$ ) and the mean outgoing longwave radiation (OLR, $\left.239 \mathrm{~W} / \mathrm{m}^{2}\right)$. By simple proportion, this is equivalent to a forcing of $108 \mathrm{~W} / \mathrm{m}^{2}$ for about $22 \mathrm{C}$ in the greenhouse effect.

Table 3: Estimation of global forcing by $20^{\text {th }}$ century irrigation based on OLR

\begin{tabular}{|c|c|c|c|c|}
\hline $\begin{array}{c}\text { OLR for } \\
288 \mathrm{~K} \text { surface }\end{array}$ & $\begin{array}{c}\text { Relative emission at } \\
\text { surface vs } 6 \mathrm{~km}\end{array}$ & $\begin{array}{c}\text { Attenuation of } \\
\text { emission }\end{array}$ & $\begin{array}{c}\text { Global land area } \\
\text { irrigated }\end{array}$ & Global forcing \\
\hline $\begin{array}{c}\text { Regional OLR in } \\
\text { dry area }\end{array}$ & $\sigma \mathrm{T}^{4}{ }_{6 \mathrm{~km}} / \sigma \mathrm{T}^{4}{ }_{\text {surface }}$ & $\begin{array}{c}50 \% \text { of spectrum by } \\
\text { water }\end{array}$ & $0.006(0.6 \%)$ & \\
\hline & $\mathrm{x} 0.57$ & $\mathrm{x} 0.5=65 \mathrm{~W} / \mathrm{m}^{2}$ & $\mathrm{x} 2.5^{*}$ dispersion & \\
\hline $300 \mathrm{~W} / \mathrm{m}^{2}$ & $\mathrm{x} 0.43=129 \mathrm{~W} / \mathrm{m}^{2}$ & $\mathrm{x} 0.015$ & $0.98 \mathrm{~W} / \mathrm{m}^{2}$ \\
\hline
\end{tabular}

Note: Relative OLR $(\mathrm{O})$ is estimated by comparing surface emission at $288 \mathrm{~K}$ to that from $6 \mathrm{~km}$ at $250 \mathrm{~K}$, if water vapour is present because of irrigation. Since $(250 / 288)^{4}=0.57$ is the Stefan-Boltzmann temperature factor, regional OLR is reduced to $300 \times 0.43 \times 0.5=65 \mathrm{~W} / \mathrm{m}^{2}$; * possibly an underestimate, given dispersion and the greater greenhouse effect at lower pressures

From Table 3, the primary sensitivity for warming predicted by water vapour from the area irrigated generated substantially between 1960 and 2000 is estimated as $0.98 \mathrm{~W} / \mathrm{m}^{2}$, providing an increased global temperature without feedback of $0.20{ }^{\circ} \mathrm{C}$. This depends on the extra irrigation water maintaining sufficient extra water vapour in air to contribute to all three sources of warming shown in Figure 2. $\mathrm{CO}_{2}$ is attributed about $20 \%$ of the natural greenhouse effect, about $6.6 \mathrm{C}$ of warming derived from $31.0 \mathrm{~W} / \mathrm{m}^{2}$ of climate forcing, assuming temperature increases occur by mechanisms independent of the source of forcing. The extra forcing caused by the increase in $\mathrm{CO}_{2}$ from $319 \mathrm{ppmv}$ to $370 \mathrm{ppmv}$ (5.3/n[370/319] [2] between 1960 and 2000 is $0.79 \mathrm{~W} / \mathrm{m}^{2}$, also equivalent to an increased global temperature without feedbacks of $0.20{ }^{\circ} \mathrm{C}$. This approach to estimating primary forcing may be regarded as too simplistic. However, no other approach to solving this problem such as using global climate models (GCMs) can be verified as superior in accuracy, given the obvious difficulties in integrating and verifying the worldwide system. Statistical errors are additive in effect. Furthermore, these 
estimates regarding extra water vapour from irrigation can be verified using data from the El Nino-La Nina cycles from the NOAA website on the variation in global water content of the atmosphere, temperature range and variation in outgoing longwave radiation (OLR) (Fig. 3). For a 4\% variation observed in water content [22] , equivalent to about $500 \mathrm{~km}^{3}$ of liquid, a variation in temperature greater than $0.8 \mathrm{C}$ with a global variation in OLR of $4 \mathrm{~W} / \mathrm{m}^{2}$ was recorded in two successive cycles.

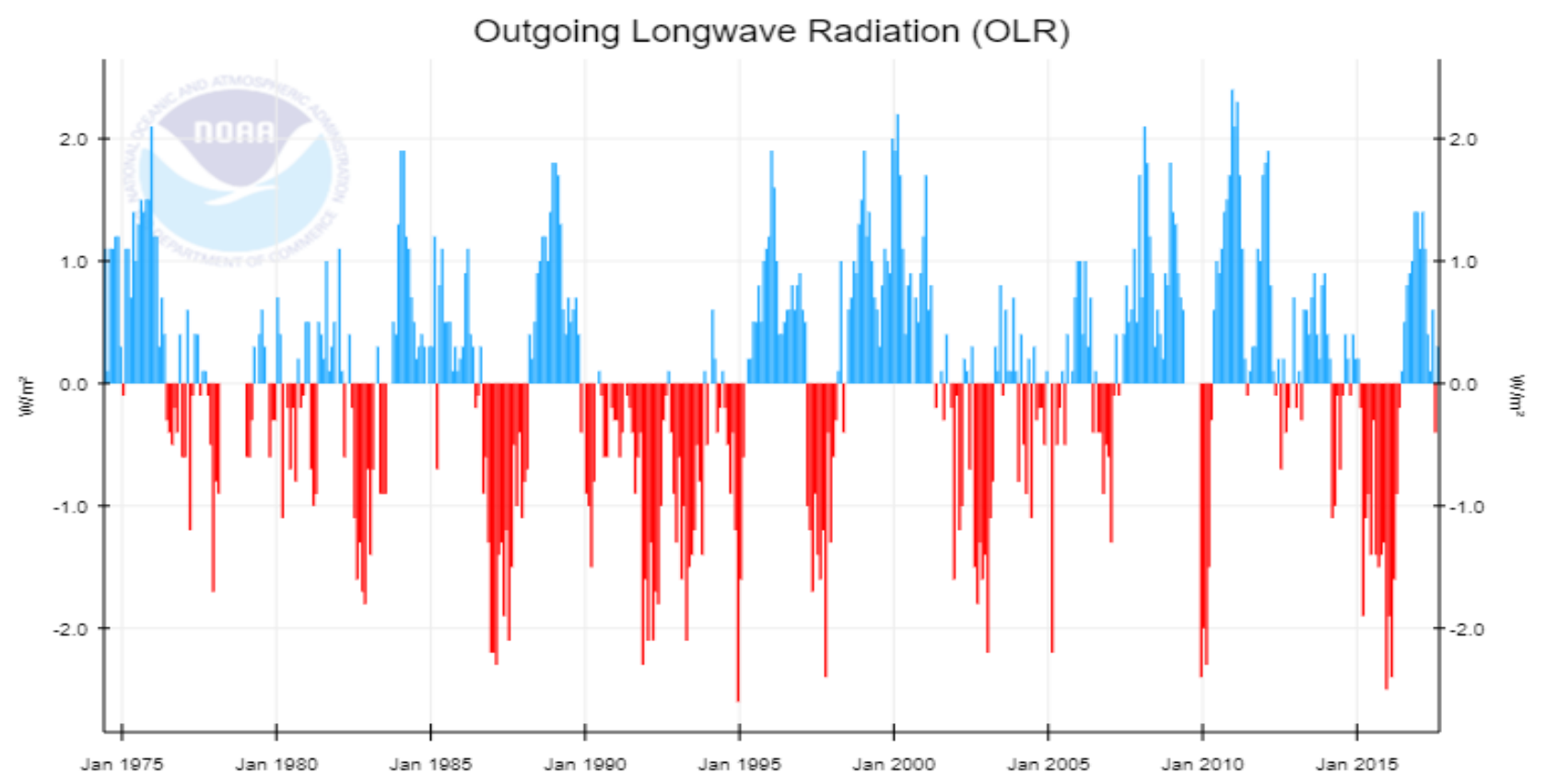

Fig. 3 Satellite measurements of global-zonal OLR (http://www.cpc.ncep.noaa.gov/data/indices/olr NOAA website, downloaded August 20, 2017). The 1998-2000 El Nino peaked at about $1.03 \mathrm{C}$ above the minimum temperature in the preceding La Nina, with zonal OLR varying approximately $4 \mathrm{~W} / \mathrm{m}^{2}$; see also (8)

This is regarded as a result of convective elevation of the maritime atmosphere, reducing the outgoing longwave radiation (OLR) about $100 \mathrm{~W} / \mathrm{m}^{2}$ locally and $4 \mathrm{~W} / \mathrm{m}^{2}$ globally from an increase in global water vapour of about $4 \%$. This suggests a linear response from greenhouse warming to increased water vapour content of the atmosphere. Note that the extra heat in the atmosphere during an El Nino is controlled by all these sources of warming, as shown in Figure 2. Whatever the source of extra heat in the ocean, by moving extra water into the atmosphere as vapour it warms the atmosphere by the resultant greenhouse effect, reducing OLR, as well as direct warming by sunlight in the air column. In Table 4, another estimate of the possible effect of irrigation on global warming by comparison with the El Nino-La Nina cycle [22] is made. Consistent with the irrigation water hypothesis the El Nino has been long known to significantly reduce the OLR over the Pacific Ocean up to 25\% [3], recognised as a result of elevation of emission of the OLR from water being elevated and therefore a colder altitude. Assuming $60 \%$ of irrigation water becomes vapour in the troposphere and a longer rain-out time of 15 days in dry regions compared to less than a week over the oceans with a global average of 8.5 days [19], a steady state of about $100 \mathrm{~km}^{3}$ of extra water vapour results from irrigation.

Table 4: Effect of global variation in atmospheric water content and greenhouse forcing

\begin{tabular}{|c|c|c|c|}
\hline Item & $\begin{array}{c}\text { Quantity water } \\
\text { vapour } \mathrm{km}^{3}\end{array}$ & Forcing W/m ${ }^{2}$ & Warming effect ${ }^{\circ} \mathrm{C}$ \\
\hline Global atmosphere & 12,750 & 108.5 & 23.8 \\
\hline El Nino - La Nina & $510^{1}$ & $4.2^{2}$ & 0.92 \\
\hline $\begin{array}{c}\text { Global irrigation since its large scale } \\
\text { inception (1950-2010) }\end{array}$ & $100^{*}$ & 0.84 & 0.19 \\
\hline
\end{tabular}

*Steady state increase in water vapour is estimated assuming a rain-out time on dry land of 15 days (19) given $60 \%$ of annual $4,000 \mathrm{~km}^{3}$ is volatilised; (22) (8) 
This estimate also suggests an increase in temperature near $0.2{ }^{\circ} \mathrm{C}$ from $0.84 \mathrm{~W} / \mathrm{m}^{2}$ of forcing based on the data given in Figure 3. This is consistent with the total effect of water vapour on global warming exceeding $25 \mathrm{C}$. It should be noted that this dynamic effect of water on warming air includes heat pumping by evapotranspiration as well as significant warming by direct absorption of short wave solar radiation (see Fig. 2 ), also contributing to a more linear effect by water on warming. Since this increase estimates a primary forcing effect of new water, a positive feedback is also anticipated from increased evaporation of the ocean, suggesting that the total increase from irrigation could be of the order of $0.5{ }^{\circ} \mathrm{C}$ in the $20^{\text {th }}$ century. These global results may have more accuracy than the results obtained from the numerous grid points in global circulation models, given the additivity of errors.

\subsection{Critique of Recent Modelling of Effect of Irrigation}

The cooling effect on surface temperature from irrigation is strongly substantiated by many studies. The Indian sub-continent is recognised as being more than $1 \mathrm{C}$ cooler as a result of the extensive surface and ground water irrigation practised there, [16]. Partly because of this strong cooling surface effect, in their review it was concluded that the effect of irrigation on global climate was negligible. But no analysis was conducted of the effect of adding water to dry areas where irrigation is usually practised. In this context, [4] were the first to propose the hypothesis that water vapour from global irrigation might have a significant human effect on climate. This was based on the idea that additional water vapour in the atmosphere should directly lead to an increased greenhouse effect and absorption of solar radiation as suggested above, by reducing the OLR in irrigated areas. While the global forcing from extra water vapour they modelled reached $0.10 \mathrm{~W} / \mathrm{m}^{2}$ in dry conditions, less than that estimated here in Table 3 from general arguments. They concluded from their modelling results that irrigation can represent an important mechanism for climate change. The significance of this effect was sufficient that it was recommended that the effect of irrigation should be included more routinely in future GCMs. To reassess this proposal, Cook et al. (2014) of the Goddard Space Center conducted a coupled model inter-comparison project. In one model experiment they added a dataset of historically estimated irrigation rates, compared to a baseline model. They found from the GCM (GISS Model2) modelling that irrigation had a negligible effect on the global average radiative balance at the top of the atmosphere, but causes significant cooling of global average surface temperatures over land. However, they noted Boucher's opinion in [4] that the standard radiative forcing concept might be difficult to apply to irrigation because of various feedbacks, raising the possibility the modelling is flawed. As a result, despite finding an even smaller forcing effect than shown by [4], they still agreed that irrigation should be considered as an important anthropogenic forcing in the next generation of multi-model assessments. However, their conclusion in [6] of a negligible effect was based purely on the model results with no verification from actual climate observations in irrigated regions that would be more sensitive to such warming. Surprisingly, particularly for dry areas, the modelling produced no evidence for an enhanced greenhouse effect from the additional water vapour generated by irrigation, as proposed by [4] .They even suggested that regional observations in Europe apparently supporting [4] hypothesis needed reassessment, rather than their modelling. No explanation for the predicted results being absent was given, apart from the bland statement that "increased longwave trapping from enhanced near surface humidity is small". Given the scale of evapotranspiration necessarily resulting from growing crops in dry areas, this conclusion from the modelling seems not credible. Another feature of the comparison was a large effect of irrigation on cloud formation, particularly in areas of higher humidity such as in China, though not over dryer India. Low-lying cloud radiating as black bodies is acknowledged to have a cooling effect on climate, in contrast to the warming effect of less absorptive cirrus cloud at high altitude. However, the net effect of clouds is not well established [1]. Furthermore, the net radiation at the top of the atmosphere as modelled was strongly disrupted by the cooling effects of several episodes of volcanic eruptions in the period from 1960 to 2000, when the major comparison of global model versus global model with irrigation was made. In India where cloud formation was not an issue there was no indication of an enhanced greenhouse effect from the extra evapotranspiration, even in a climate known to be in strong water deficit and sufficient to significantly cool the region. Given that the output of the GISS Model2 GCM modelling produced a global result including any effects over the oceans, there is a risk that the modelling lacked the sensitivity required for such a highly dispersed effect, only a fraction regionally of that occurring in a typical El Nino. The authors concluded that targeted regional modelling tested by real time observations would have much higher sensitivity and should be 
more capable of testing the hypothesis of [4]. Indeed, we concur with this conclusion and suggest that direct observations (i.e. of evapotranspiration and variations on OLR) in irrigated regions are essential to properly test the water hypothesis presented here.

\subsection{Comparing the Effect of Irrigation on Dryland to the El Nino}

In Figure 4, using the same modelling as in Figure 2, the predicted steady state greenhouse effect of adding irrigation water in a comparison between dryland and irrigated land. In fact the effect of water on heat transfer to the atmospheric column is not only a result of the greenhouse effect given in the equation in the figure but also from direct absorption by water of short wave ISR and evapotranspiration, similar in total magnitude. These latter effects will be a linear function of the water vapour involved. The evaporative effect cools the surface but must transfer a similar amount of heat to the atmosphere as infrared radiation (ca. 6 microns) associated with condensation of water vapour into droplets under convective cooling as in [21]. Paradoxically, the modelling paper in [6] failed to account for any of these effects, specifically dismissing significant transfer of water vapour into the atmosphere from growth of irrigated crop growth as noted above. This provides a clue to the possible flaw in their models. Except for environments already very humid where evapotranspiration is limited, this cannot be true.

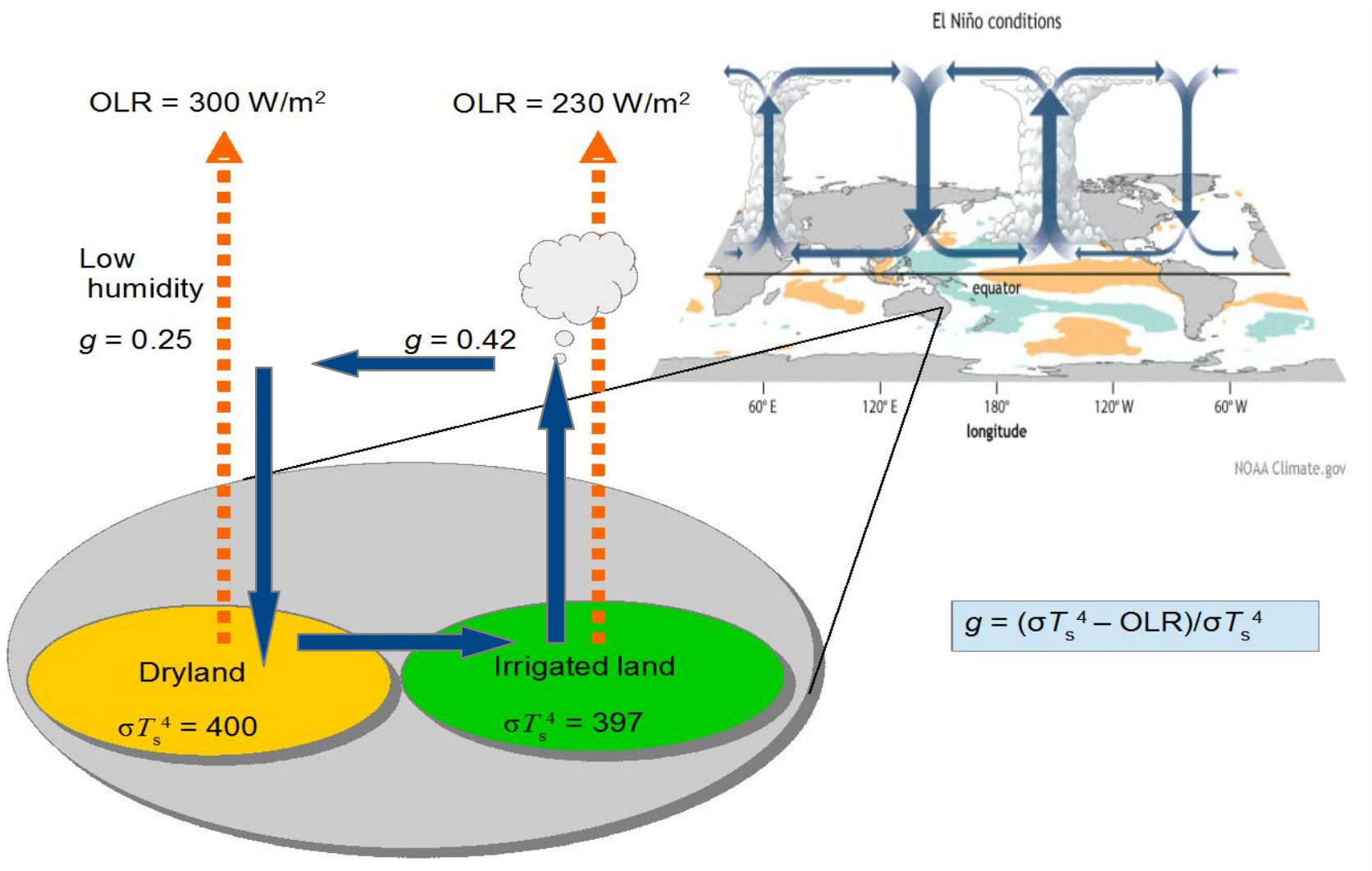

Fig. 4 Comparison of dryland and irrigated land for effect of water on heat retention in the atmosphere as an enhanced greenhouse effect. The El Nino condition of enhanced evaporation from the ocean known to strongly reduce OLR In [3] is shown as an analogue.

\section{New Results}

\subsection{NCEP/ NCAR Reanalyses Coincident with the Periodic Flooding of Lake Eyre}

Rarely, during the La Nina phase of the climate cycle, the dry interior of northern Australia overlying the Great Artesian Basin may flood. Lacking riverine exits to the ocean, the massive runoff caused flows southwards, mainly accumulating in the depression below sea level in central South Australia known as Lake Eyre. In late January and February in the early months of 1974 Lake Eyre filled to a depth of six metres, its 
surface only returning to its hot, dry state three years later in 1977-78. This was the greatest flood ever recorded. The hypothesis in [4] suggests that this flooding should also lead to persistent elevated water vapour content of the atmosphere, predominantly downwind from the Lake Eyre basin. Using the NCEPNCAR reanalysis datasets, which are informed by Nimbus and other satellite observations since 1970, the OLR emissions to space and the variation in humidity from this region comparing 12 months of 1974 with the same period in 1978 by subtraction of one year from the other. A significant elevation of OLR when the lake was dry by more than $10 \mathrm{~W} / \mathrm{m}^{2}$ was observed for the 12-month period (Figure 5). This result is accompanied by increases in specific humidity consistent with an elevated greenhouse effect such as would be experienced in semi-arid areas when irrigated. The area affected downwind also showing elevated humidity is estimated as 35 times the flooded area, showing that the magnitude of this regional greenhouse effect was indeed significant. These direct observations for a process similar to applying irrigation water to dry land cast further doubt on the lack of a similar response in the modelling exercise of Cooke et al. Thus, given the other estimates of possible warming from extra water, there is a strong likelihood that the modelling exercises in [4] and particularly in [16] lack the correct inputs for accuracy; in particular, the dispersion of water vapour over a greater area than that irrigated needs investigation. In Table 3 a 2.5 -fold dispersion factor was used but this may be an underestimate as the greenhouse effect from water is relatively greater as the specific humidity diminishes [15] with as much effect between 0 and $0.1 \mathrm{RH}$ as between 0.2 and 0.5 . Visual inspection of Figure 5 indicates a far greater dispersion factor of the order of 10 times, indicating an effect of the order of $100 \mathrm{~W} / \mathrm{m}^{2}$ if restricted to the area of surface water.
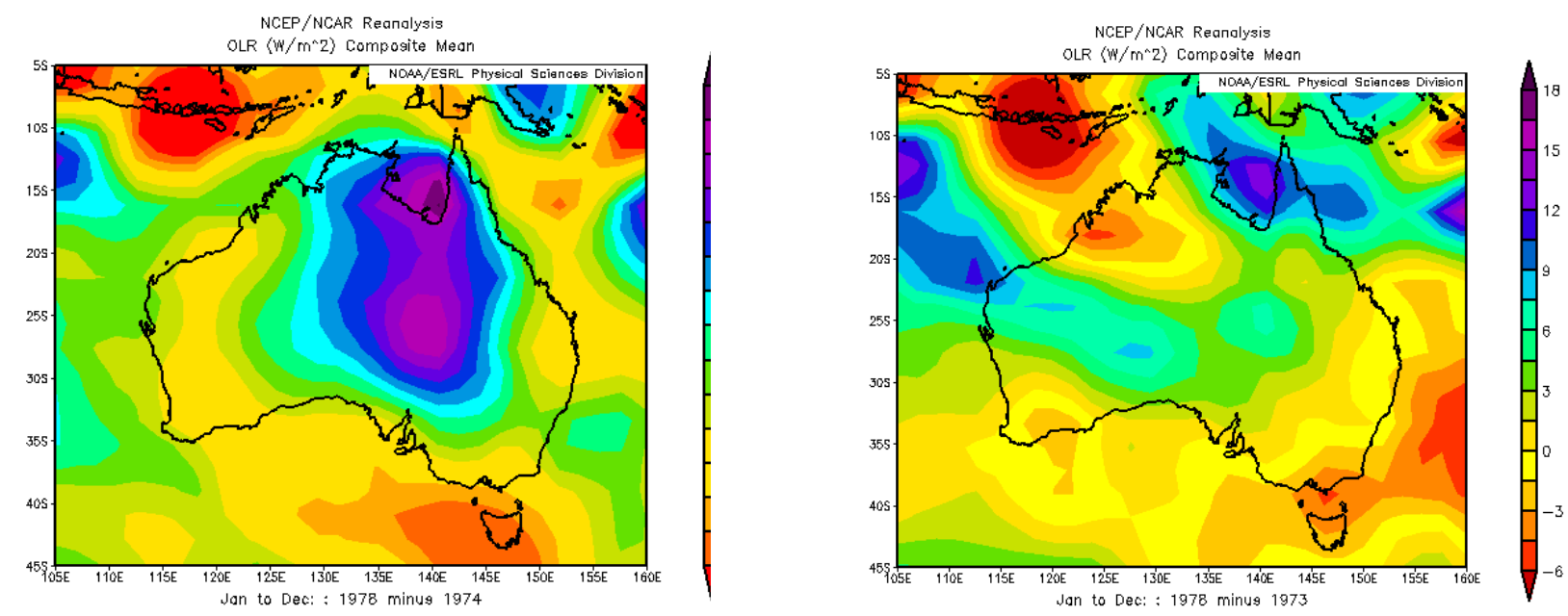

Fig. 5 Variation in OLR from flooding of lake Eyre using NCEP-NCAR reanalysis datasets. a. Difference in OLR values between 1978 and 1974, dry and wet years.

b. Difference in OLR values between 1978 and 1973, two dry years. Plots generated by https://www.esrl.noaa.gov/psd/cgi-bin/data/composites/printpage.pl

\section{Conclusion}

The neglect of the possible effect of irrigation as a significant source of anthropogenic climate change may have been a result of reluctance to consider the relatively small amount of irrigation in the hydrological cycle. Because water has been considered as providing positive feedback to warming primarily from $\mathrm{CO}_{2}$ its possible forcing effect has been overlooked. But as shown here by several different means, the more potent effect of applying water previously in the ocean or deep in the ground to dry surfaces with air in strong water deficit can be sufficient to affect global temperature. Clearly, the water vapour content of the troposphere is the major cause of the natural greenhouse effect, contributing up to two-thirds of the $33{ }^{\circ} \mathrm{C}$ warming. Spatial and temporal variations in soil moisture and relative humidity of the atmosphere are the main factors controlling the regional outgoing longwave radiation (OLR), in contrast to the more even effects from well-mixed greenhouse gases such as $\mathrm{CO}_{2}$. This is well illustrated in the 4-6 year El Nino cycles, resulting in a global mean temperature variation approaching $1{ }^{\circ} \mathrm{C}$ compared with La Nina years. Longer term, the proposed Milankovitch glaciations of paleoclimates result in declines of atmospheric temperature around $10{ }^{\circ} \mathrm{C}$, 
consistent with the major reduction in tropospheric water vapour approaching 50\%. Weather conditions and climate as illustrated in the greenhouse effect are clearly demonstrated in the distribution of water, particularly on land. The apparently linear relationship between the water content of the atmosphere is direct verification of the greenhouse warming effect of this greenhouse gas. By contrast, other than by correlation, there is no such direct verification possible for the greenhouse effect of $\mathrm{CO}_{2}$. We rely on the forcing equation of $5.3 \ln \left[\left(\mathrm{CO}_{2}\right)_{t} /\left(\mathrm{CO}_{2}\right)_{\mathrm{o}}\right]$ to estimate the climate sensitivity with respect to varying concentration (ppmv) of this greenhouse gas. Early hopes that a clear spectral signal was available showing significantly reduced OLR from increasing $\mathrm{CO}_{2}$, proving the hypothesis of climate forcing by permanent GHGs, have not been realised [5]. A focus using new satellites on the longer wavelength OLR associated with rotations of water might help resolve this question. Up till now, OLR is estimated for this region based on shorter wavelengths. The natural experiment provided by the flooding of Lake Eyre of the greenhouse effect by significantly reducing the OLR provides confirmation that irrigation water typically applied to dry land will have a measurable greenhouse effect. This work should be repeated using satellite data of higher resolution obtained over irrigated land. In [7] Davis et al. have recently drawn attention to the possibility of significant water use efficiency through optimised crop distribution. If it is true that increased use of water has made a similar contribution to global warming as $\mathrm{CO}_{2}$ since 1960 , there is an equally strong case to provide greenhouse credits to promote water use efficiency as for restricting evolution of permanent GHGs.

\section{References}

[1] Aldrin M, Holden M, Guttorp P, Skeie RB, Myhre G, Berntsen TK (2012) Bayesian estimation of climate sensitivity based on a simple climate model fitted to observations of hemispheric temperatures and global ocean heat content. Environ 23:253-271

[2] Andrews D An Introduction to Atmospheric Physics. Cambridge University Press, $2^{\text {nd }}$ Edition, Cambridge UK. (2010)

[3] Ardunay PE, Lee Kyle H (1986) El Nino and outgoing longwave radiation: Observations from Nimbus-7 ERB. Amer. Meteor. Soc., Monthly Weather Review February: 415-433

[4] Boucher O, Myhre G, Myhre A (2004) Direct human influence of irrigation on atmospheric water vapour and climate. Clim Dynam 22:597-603

[5] Brindley HE, Bantges RJ (2016) The spectral signal of recent climate change. Curr Clim Change Rep 2:112-126

[6] Cook BI, Shukla SP, Puma MJ, Nazarenko LS (2014) Irrigation as an historical climate forcing. Clim Dynam 44:1715-1730

[7] Davis KF, Rulli MC, Seveso A, Odorico P. (2017) Increased food producton and reduced water use through optimized crop distribution. Nature Geosci 10:919-924

[8] Dessler E, Wong S (2009) Estimates of the water vapor climate feedback during El Nino-Southern Oscillation. J Climate 22:6404-6412

[9] de Marsily G, Abarca-del-Rio R (2016). Water and food in the twenty-first century. Surv Geophys 37: $03-527$

[10] Giorgio GP (2014). https://commons.wikimedia.org/w/index.php?curid=155810, search term OLR, June 24, 2014; downloaded Wikimedia, July 12, 2017

[11] Kennedy IR (2015) Computation of planetary atmospheres by action mechanics using temperature gradients consistent with viral theorem Int J Energy Environ 9:129-146

[12] Kiehl JT, Trenberth KE (1997). Earth's annual global mean energy budget. Bull Amer Meteor Soc 78:197-208

[13] Lacis AA, Schmidt GA, Rind MD, Ruedy RA (2010) Atmospheric $\mathrm{CO}_{2}$ : Principal control knob governing Earth's temperature. Science 330:356-359

[14] Myhre G, Myhre A, Stordal F (2001) Historical evolution of radiative forcing of climate. Atmos Environ 35:2361-2373

[15] Pierrehumbert RT (2010) Principles of Planetary Climate. Cambridge Press New York

[16] Pitman AJ, Arneth A, Ganzeveld L (2012) Review: Regionalizing global climate models. Int J Climatol 32:321-327

[17] Plusquellec $\mathrm{H}$ (2002). Is the daunting challenge of irrigation achieveable. Irrig Drainage 52: 185-198

[18] Puckrin E, Evans WFJ, Lavoie H (2004). Comparison of clear-sky radiative fluxes simulated with radiative transfer models. Canad J Remote Sens 30:903-912 
[19] van der Ent RJ, Tuinenburg OA (2017) The residence time of water in the atmosphere revisited. Hydrol Earth Systems Sci 21:779-790

[20] Schmidt GA, Ruedy RA, Miller RL, Lacis AA (2010) Attribution of the present-day total greenhouse effect. J Geophys Res 15:D21106

[21] Tatartchenko V, Liu Y, Chen W, Smirnov P (2012). Infrared characteristic radiation of water condensation and freezing in connection with atmospheric phenomena: Experimental data. Earth-Sci Rev $114: 218-223$

[22] Trenberth KE, Smith L (2005) The mass of the atmosphere: A constraint on global analyses. J Climate 18:864-875

[23] Trenberth KE, Fasullo JT, Mackaro J (2011) Atmospheric moisture transports from ocean to land and global energy flows by reanalyses. J Climate 24:4907-4924

[24] Trenberth KE, Caron JMD, Stepaniak P, Worley S (2002), The evolution of ENSO and global atmospheric surface temperatures, J Geophys Res 107:(4065) D8

[25] Oubrahim Y, Lbazri S, Ounacer S, Rachik A, Moulouki r, Azzouazi M, "A New Architecture for monitoring Land use and land cover change based on remote sensing and GIS: A Data mining Approach", PEN, 6:2, 406-416, 2018.

[26] Yakubovich AN, Trofimenko YV, Yakubovich IA, Shashina EV, "A forecast model for a road network's section traffic capacity assessment on a territory of the cryolithozone in conditions of the climate change", PEN, 7:1, 275-280, 2019.

[27] Sengupta PP, Sinha M, Dutta UP, "Economic and environmental performances in manufacturing industries: A comparative study", PEN, 7:1, 99-108, 2019. 